\title{
LA AUDIENCIA ARZOBISPAL COMPOSTELANA EN EL SIGLO XV: INTRODUCCIÓN A SU ESTUDIO DIPLOMÁTICO
}

\author{
Por \\ MERCEDES VÁZQUEZ BERTOMEU
}

Derivada de su función pastoral, los obispos adquirieron ya en los primeros tiempos del cristianismo potestad para corregir las faltas de sus fieles; progresivamente, la facultad se extendió al clero, al patrimonio eclesiástico e incluso a la ciudad episcopal. En la Edad Media, la jurisdicción episcopal atiende a una gran variedad de asuntos ya que las competencias del tribunal se establecen en una doble vertiente: por razón de las personas y por las materias ${ }^{1}$. Por las personas a quienes se enjuicia, pertenecen al tribunal eclesiástico todas las causas relativas a los clérigos, tanto en cuestiones que les afectan como individuos como las referentes a sus bienes; pero también huérfanos y viudas tienen derecho a acudir a la justicia de la Iglesia. Por la materia que se juzga, la corte episcopal conoce, en principio, asuntos de índole espiritual así como todos los referentes al patrimonio eclesiástico; afecta, pues, a temas como el matrimonio -con todo lo que ello conlleva (separaciones, legitimidad de los hijos, dotes, adulterios)-, la usura, ruptura de juramento, testamentos, sacrilegios, crímenes contra la fe y los sacramentos, simonía, ataques a la inmunidad y patrimonio de la Iglesia, diezmos, beneficios, derechos de presentación, etc.

\footnotetext{
' FOURNIER, P.: Les officialités au Moyen Âge. Paris, 1880=Aalen, 1984; pp. 64-94; esta obra clásica sigue siendo fundamental; LOT, F.; FAWTIER, R.: Histoire des institutions françaises au Moyen Age: t. III: Instituciones ecclésiastiques. Paris, 1962; p. 271-73.
}

"CUADERNOS DE ESTUDIOS GALLEGOS", Tomo XLV, Fascículo 110, Santiago 1998. 
La Iglesia desarrolló en las diócesis un entramado judicial organizado jerárquicamente. En su base están los tribunales de los arciprestes, cuyo funcionamiento y atribuciones están reconocidas por el derecho canónico y cuya existencia en Galicia nos confirman los sínodos ${ }^{2}$. Por encima de ellos, los tribunales de $\overline{\text { los }}$ arcedianos. Como delegados territoriales del obispo, éstos juzgan en apelación los casos vistos en los tribunales de los arciprestes, pero también algunas de las causas que corresponden a la jurisdicción arzobispal como los matrimonios o la ejecución de testamentos. En estos juzgados, siguiendo las normas canónicas, el juez estaría asistido por un escribano -posiblemente un notario apostólico- que levanta acta de las vistas ${ }^{3}$. Su existencia también está testimoniada por las fuentes. Por encima de ellos, la justicia ejercida por el obispo -la audiencia episcopal-que ve las causas sólo a él reservadas y las apelaciones de los tribunales inferiores. Tras esta instancia sólo cabe el recurso al juzgado metropolitano y a la corte romana. Las atribuciones de esta corte recaen en el caso compostelano en un tribunal cuya sede parece estar en la ciudad de Salamanca ${ }^{4}$.

Los obispos fueron abandonando el ejercicio personal de la justicia en manos de colaboradores. Las primeras menciones de la existencia de estos servidores se remontan en algunas diócesis europeas a la primera mitad del siglo XII de un modo un tanto impreciso y, más claramente, en los años siguientes ${ }^{5}$. La aparición e implantación de este juez, en principio delegado, se relaciona estrechamente con la recuperación del derecho y el establecimiento del procedimiento judicial romano-canónico. Esta nueva realidad hace necesaria la concurrencia de personal capacitado. Contemporáneamente, se asiste a la progresiva independencia de la curia judicial.

${ }^{2}$ GARCÍA Y GARCÍA, A. (dir): Synodicon Hispanum: v. I Galicia, Madrid, 1981; Synod. Aur. 1543-44, tit. 25, c.3.

${ }^{3}$ Sobre los tribunales arcedianales vd. BOWKER, M.: «Archdeacons' court books and the Commons' supplication» en The study of medieval records. Essays in honour of Kathleen Major. Oxford, 1971; pp. 282-316.

${ }^{4}$ Archivo Histórico Diocesano de Santiago (AHDS), Fondo General, Leg. 501, 1, f ${ }^{\circ}$ $19 \mathrm{v}, 20 \mathrm{v}$. No obstante, algunas de sus causas son vistas directamente por el prelado o su provisor (PORTELA SILVA, M.J.: La colección diplomática de la catedral de Lugo (s. XIV y XV). Tesis doctoral inédita. Santiago de Composela, 1993, doc. $\mathrm{n}^{\circ} 1329$ ).

${ }^{5}$ LE BRAS, G.: «Le istituzione ecclesiastiche della Cristianità medievale» en Storia della Chiesa dalle origini ai nostri giorni. Torino, 1973; v. XII/1; pp. 166-168.

"CUADERNOS DE ESTUDIOS GALLEGOS", Tomo XLV, Fascículo 110, Santiago 1998. 
Finalmente, el officialis se encargará, casi en exclusiva, de presidir el tribunal episcopal, juzgando según el derecho común eclesiástico y con poder para pronunciar sentencias y todo tipo de censuras eclesiásticas ${ }^{6} ; 1 \mathrm{a}$ audiencia tendrá sede estable y única con personal fijo a su servicio. En 1246, la decretal Romana ecclesia -recogida en las compilaciones posteriores y ampliamente comentada por los canonistas- confiere a este personaje la calidad de juez ordinario ${ }^{7}$, si bien para ver determinadas causas ha de disponer de un mandato expreso del prelado (generalmente conferido).

La Historia Compostelana da las primeras informaciones acerca del ejercicio de la justicia episcopal en esta diócesis. Según en ella se relata, existe un entramado judicial -posiblemente en estado rudimentario-, que en Santiago se materializa en la presencia del villicus y los dos iudices Loci Sancti ${ }^{8}$; sus competencias no están muy claras, sin embargo, parecen corresponder al primero los asuntos posteriormente reservados a la justicia seglar. Los iudices Loci Sancti, que en este momento son dos canónigos, atenderán las demás causas de la ciudad y sus contornos. Esta obra presenta también la imagen del prelado impartiendo personalmente justicia sobre laicos y clérigos ${ }^{9}$. Los decretos que se promulgan en 1113 para preservar la justicia en la Tierra de Santiago, señalan los asuntos que juzgan estos iudices: causas sobre heredades e iglesias, testamentos y herencias ${ }^{10}$. Las escrituras referentes a estos asuntos habrán de ser redactadas por clérigos autorizados o por los mismos jueces ${ }^{11}$. Todos los viernes, se celebrará en el palacio episcopal vista pública, presidida por el prelado $^{12}$.

\footnotetext{
${ }^{6}$ Ibidem; LOT, F.; FAWTIER, R.: op. cit, pp. 259-260.

${ }^{7}$ LE BRAS, G.: loc. cit.

${ }^{8}$ Historia Compostelana, L. 1, cap. 96; L. 2, cap. 68. Quizás haya que ver en estas judicaturas los precedentes de las dignidades de jueces de Luou y Villestro, que ya a final de la Edad Media aparecen como dignidades ordinarias, en todo caso de los dos jueces -generalmente canónigos- que juzgarán en la Quintana.

${ }^{9}$ La crónica, aún con un fondo real, podría también remitir a tópicos cuya finalidad sería reforzar la imagen de prelado.

${ }^{10}$ Historia Compostelana, L. 1, cap. 96, decretos 3 y 18.

"Ibidem decreto 10.

${ }^{12} \mathrm{Ib}$., decreto 14 .
}

"CUADERNOS DE ESTUDIOS GALLEGOS", Tomo XLV, Fascículo 110, Santiago 1998. 
Las fuentes no permiten establecer con exactitud la evolución de esta administración judicial. Un texto del siglo XIII recogido en las constituciones capitulares, se refiere a las competencias de los antiguos iudices Loci Sancti, ahora iudices Sancti Iacobi: ven en apelación todo tipo de causas procedentes de todo el territorio compostelano y en primera instancia aquellos asuntos cuyos actores reclamen el dictamen de este tribunal ${ }^{13}$. Precisamente esta intervención en todo tipo de negocios será denunciada por el concejo en un famoso proceso llevado ante el rey. Las sentencias de Alfonso $\mathrm{X}^{14}$, que recogen importantes informaciones acerca del ejercicio de la justicia en la ciudad, conminan a la justicia eclesiástica a abandonar los juicios de sangre y aquellas causas vistas tradicionalmente por los alcaldes concejiles ${ }^{15}$. Denuncian, asimismo, la utilización del derecho canónico recién promulgado (decreto y decretales) en los procesos seguidos en estos tribunales ${ }^{16}$. El panorama descrito, concreta la existencia de un tribunal presidido por los jueces eclesiásticos con actividad regular y otro -quizás más ocasional- presidido por el arzobispo.

Por el momento es imposible establecer en qué momento comenzaron los prelados a delegar de manera habitual las funciones judiciales. Inicialmente, los nombramientos en este sentido tendrían su origen en sus frecuentes ausencias. Las primeras menciones a la existencia del officialis -como juez único que asume competencias reservadas al prelado- no aparecen en las fuentes compostelanas hasta el siglo XIV; pero hay que dar como casi segura su presencia al menos desde el período posterior al fallecimiento de D. Juan Arias. En estos años, los prelados fueron despojados del señorío sobre la ciudad siendo más frecuentes los viajes a la corte $^{17}$.

${ }^{13}$ Texto publicado por LÓPEZ FERREIRO, A.: Fueros de Santiago y su Tierra. Reimp. A Coruña, 1991, pp. 94-95 (ACS, Libro de Constituciones $2^{\circ}, \mathrm{f}^{\circ}$ 55r).

${ }^{14}$ Ibid., pp. 251-260, 264-277, 282-289.

${ }^{15}$ Estos asuntos aparecen claramente mencionados en un documento de 1346 publicado por LÓPEZ FERREIRO, A.: Fueros, pp. 344-347.

${ }^{16}$ Que los yuizes no quieren iudgar segunt uso et costumbre de la uilla, et que iudgan por sus leys romanas. (op. cit., p. 274).

${ }^{17}$ Ya este prelado dispuso en sínodo provincial normas acerca de los tribunales eclesiásticos (LÓPEZ FERREIRO, A.: Historia de la Santa Apostólica y Metropolitana Iglesia de Santiago de Compostela. 11 vols. Santiago, 1898-1909; v. V, ap. 39, c. 5 y 14).

"CUADERNOS DE ESTUDIOS GALLEGOS". Tomo XLV, Fascículo 110, Santiago 1998. 
En 1314, en una carta referida a los excomulgados que desafían su autoridad, don Berenguel se refiere con claridad a las penas impuestas por él o sus antecesores y sus vicarios ${ }^{18}$. Se habla, pues, de sustitutos dotados de esta facultad en nombre del prelado. Por otro lado, el sínodo provincial de 1335, confirma la existencia de estos vicarios seu officiales, como práctica habitual en todas las instancias de la jurisdicción eclesiástica $^{19}$; se prescribe la necesidad de que sean personas versadas en leyes y se establecen aranceles para la expedición de documentos ${ }^{20}$. La aparición de este vicario arzobispal debió llevar consigo una reestructuración de la administración judicial ya que -como magistrado delegado- entra en su jurisdicción todo tipo de asuntos (incluidos los que veían los jueces eclesiásticos de la ciudad). Las características, circunstancias y cronología de esta evolución permanece desconocida. Su resultado final aparece ya a finales del siglo XIV y plenamente esclarecido en el XV.

El oficial arzobispal -denominado en ocasiones provisor-asume casi todas las competencias del prelado, unas en razón de su oficio y otras por procuración. Junto a su audiencia aparece un segundo tribunal presidido por un canónigo perito en leyes y con sede en la plaza de la Quintana, su presidente se denomina también juyz enna audiençia arçobispal, lo que sin duda induce a confusión.

Este tribunal secundario que tiene su sede en el auditorio dos pleytos de la plaza pública de la villa, juzga -a tenor de las fuentes consultadasen primera instancia causas procedentes sólo de Santiago y su distrito; el ámbito jurisdiccional abarca lo contencioso, algunos asuntos habituales de competencia eclesiástica (ejecución de testamentos) y ciertas funciones de jurisdicción graciosa. Sus documentos son autorizados por notarios de la ciudad aunque dispone de escribanos adscritos permanentemente a su servicio.

\footnotetext{
${ }^{18}$ Archivo de la Catedral de Santiago (ACS), Libro de Constituciones $2^{\circ}, f^{\circ} 34 r-35 v$

${ }^{19}$ Sínodo publicado por LÓPEZ FERREIRO, A.: Historia, v. VI, ap. 22. c. 2.

${ }^{20}$ Ibidem.
}

"CUADERNOS DE ESTUDIOS GALLEGOS", Tomo XLV, Fascículo 110, Santiago 1998. 


\section{EL TRIBUNAL}

La audiencia del provisor es la instancia judicial más importante de la Tierra de Santiago, por la amplitud de sus competencias y por su organización interna, ocupando en la jerarquía de los tribunales el lugar más alto. $\mathrm{Al}$ asumir la función del prelado, corresponde a ese oficial la jurisdicción contenciosa en todos los asuntos reservados al fuero eclesiástico y la jurisdicción graciosa acerca del cumplimiento de las leyes del prelado y la Iglesia ${ }^{21}$. Ello se concreta en la Iglesia compostelana en la capacidad de ver causas çeuiles, criminales, espirituales e tenporales ${ }^{22}$. Con frecuencia a estas capacidades derivadas de su calidad de juez ordinario, se une en Santiago su calidad de vicario en lo espiritual y lo temporal. De este modo asume competencias directamente ligadas al prelado como son la presentación, colación y provisión de beneficios eclesiásticos ${ }^{23}$.

La corte tiene su sede en la casa del provisor ${ }^{24}$. Es él quien preside las sesiones, que tienen lugar en presencia de los escribanos que llevan la escrituración del proceso. Acuden allí el fiscal, los abogados y las partes o sus procuradores. El fiscal o promotor expone la acusación y cita a los delincuentes ante el juez; asume, en fin, la representación arzobispal, encarnando la ley por él representada y promulgada. Los abogados exponen las intenciones o la defensa de sus clientes. Las partes son generalmente representadas por procuradores ${ }^{25}$.

Toda esta actividad da lugar a una estructuración de las labores del tribunal, a una organización de los diversos oficios, y a una variada

\footnotetext{
${ }^{21}$ LE BRAS, G.: op. cit., p. 169.

${ }^{22}$ ACS, Actas Capitulares (AC) I, f ${ }^{\circ} 19 r$.

${ }^{23}$ Dado que estas labores son asumidas por delegación especial pueden ser revocadas sin afectar a las judiciales tal y como ocurrió en 1467 (ACS, AC I, f $\mathrm{f}^{\circ}$ 19r).

${ }^{24}$ En efecto, las escasas noticias referentes a este asunto localizan la audiencia en este lugar (PORTELA SILVA, M.J.: La colección, $\mathrm{n}^{\circ}$ 1329). La interpretación de esta circunstancia es doble: o bien el provisor vive en unas dependencias anejas a la audiencia, o bien las vistas públicas tienen lugar en su casa, mientras que las labores de escrituración tendrían sede fija en otro lugar.

${ }^{25}$ FOURNIER, P.: Les officialités, pp. 29-41; MARSILLA DE PASCUAL, F.R.: El cabildo de la Catedral de Murcia en el siglo XV. El escritorio capitular. La chancillería episcopal. Murcia, 1993; pp. 216-218; IDEM: «Introducción al protocolo eclesiástico de Juan Sánchez, notario apostólico de Murcia» en Estudis Castellonencs, 6 (1994-1995); pp. 819-20.
}

"CUADERNOS DE ESTUDIOS GALLEGOS", Tomo XLV, Fascículo 110, Santiago 1998. 
tipología documental que hoy en día es difícil reconstruir. El procedimiento a seguir en la vista de las causas queda fijado en la procedura romano-canónica ${ }^{26}$, difundida en los numerosos ordines iudiciarii que circularon durante la Edad Media y cuya presencia en Compostela es demostrable ${ }^{27}$.

Dejando a un lado a todos aquellos que intervienen en la escrituración y validación de los procesos y al provisor, no hay información sobre otros empleados de la audiencia. Escasamente se puede esbozar el papel de otras personas tales como abogados y procuradores de las partes; o la presencia -al igual que en otras sedes- del registrator o de los diversos mensajeros y personal subalterno ${ }^{28}$. Las únicas actas procesales compostelanas conocidas proceden del tribunal de la Quintana ${ }^{29}$.

La documentación atestigua abundantemente que las partes no suelen defender personalmente sus intereses y que recurren al nombramiento de abogados y procuradores. A tenor de estos textos, a ellos incumbe la defensa de los intereses de sus representados, exponiendo los cargos y descargos, justificando y alegando las respectivas posturas, aportando las

${ }^{26}$ FOURNIER, P.: Les officialités, pp. 128-283; GARCÍA Y GARCÍA, A: «El proceso canónico medieval en los archivos españoles» en Memoria Ecclesiae IV. La catedral y la diócesis en los archivos de la Iglesia. Oviedo, 1993; pp. 65-84; IDEM: «El proceso canónico en la documentación medieval leonesa» en El Reino de León en la Alta Edad Media 2: el ordenamiento jurídico del reino. León, 1992; pp. 566-655. La escasa documentación conservada permite confirmar que en los tribunales eclesiásticos compostelanos se siguen estos procedimientos (ACS, Carpeta Documentos Sueltos 16, $\mathrm{n}^{\circ}$ 10-3; ACS, Carpeta Sueltos 16, $\mathrm{n}^{\circ} 32$; ACS, Leg. 1102A, s.f. 4-8-1486).

${ }^{27}$ GARCÍA Y GARCÍA, A.: «La biblioteca del Arzobispo de Santiago de Compostela Bernardo II» en Antonianum, 61 (1986), pp. 540-568; GARCÍA Y GARCÍA, A.: «El derecho común medieval en las bibliotecas de Galicia» en Glossae. Revista de Historia del derecho europeo, 1 (1988), pp. 189-198. VÁZQUEZ BERTOMEU, M.; RODRÍGUEZ SUÁREZ, M.P.; ALLER ÁLVAREZ, M.: «Libros y bibliotecas eclesiásticas en la Compostela del siglo XV» en Estudis Castellonencs, 6 (1994-95), pp. 1455-1464. Posiblemente un estudio más pormenorizado de la documentación permitirá establecer la influencia de estas obras en la legislación compostelana a este respecto y en los escritos procesales.

${ }^{28}$ FOURNIER, P.: op. cit., pp. 25-31; MICHEL, F.: Zur Geschichte der geistlichen Gerichtsbarkeit und Verwaltung der Trierer Erzbischöfe im Mittelalter. Trier, 1953; pp. 143-144; WOODCOCK, P.: Medieval ecclesiastical courts in the Diocese of Canterbury. London, 1958; pp. 13-14.

${ }^{29}$ ACS, Carpeta Sueltos 16, $n^{\circ} 10-3$; ACS, Carpeta Sueltos 16, $\mathrm{n}^{\circ} 32$.

"CUADERNOS DE ESTUDIOS GALLEGOS", Tomo XLV, Fascículo 110, Santiago 1998. 
pruebas y los testigos, solicitando aplazamientos, presenciando la lectura de la sentencia y presentando las oportunas apelaciones.

La vista tiene lugar ante el provisor y ante un escribano que actúa como secretario judicial; éste redacta las actas del proceso, elabora las citaciones y mandamientos del juez, da fe pública a los traslados de las pruebas documentales y a las deposiciones de los testigos y, finalmente, redacta la sentencia decidida por el magistrado. La escrituración de los procesos eclesiásticos quedó determinada por el IV concilio de Letrán con vista a facilitar la ejecución de los procesos de apelación ${ }^{30}$.

\section{LA ORGANIZACIÓN INTERNA DE LAS TAREAS DOCU- MENTALES}

Dada la importancia que en la audiencia tiene la escrituración de los asuntos, se desarrolló una organización y división en las tareas. Como personal adscrito a esta función mencionan las fuentes la existencia de dos tipos de profesionales, el scripuan y el notario. Según las cartas de nombramiento de escribanos judiciales conocidas en Galicia, estos individuos redactan los autos judiciales y escrituras relativas a ellos ${ }^{31}$; sus documentos tendrán validez pública por el mandato episcopal contenido en el documento, siempre y cuando la escritura contenga el dia, mes e año $e$ lugar e los testigos que a ello fueron presentes e vuestro signo. Según se desprende de estos textos, los escribanos -que con cierta frecuencia son escribanos de cámara del rey- limitan su intervención a aquellas tareas que no invaden las competencias de los notarios públicos ordinarios: la redacción de las actas procesales, los mandamientos judiciales o las citaciones $^{32}$. En ningún caso están habilitados para interferir en el ámbito de los notarios públicos ${ }^{33}$. Participan también, posiblemente, en la escrituración de cartas que luego autorizarán los notarios.

\footnotetext{
${ }^{30}$ Canon 38 de este concilio recogido en las decretales gregorianas (X. 2.19.11).

${ }^{31}$ RODRÍGUEZ GONZÁLEZ, A.: Livro do Concello de Pontevedra. Pontevedra, 1989, fo 90r; ACS, Leg. 702, f ${ }^{\circ}$ 54r-54v, 304r-304v.

${ }^{32}$ Ibidem.

${ }^{33}$ De hecho uno de los escribanos de la audiencia fue privado en 1404 de su oficio de escribanía por ejercer como notario público (LÓPEZ FERREIRO, A.: Historia, v. VII, p. 10; ACS, Tumbo H, $2^{\text {a }}$ fol., $\left.f^{\circ} 6 v\right)$.
}

"CUADERNOS DE ESTUDIOS GALLEGOS", Tomo XLV, Fascículo 110, Santiago 1998. 
Los personajes que trabajan en este tribunal son generalmente notarios apostólicos, reales, arzobispales ${ }^{34}$ o nombrados especialmente para ejercer en la audiencia ${ }^{35}$; son ellos los encargados de dar fe a las escrituras públicas emanadas de los actos acontecidos en la audiencia o ante el provisor: sentencias, provisión de beneficios, autorización de traslados, etc. Los notarios -a tenor de sus suscripciones- redactan la primera nota del documento; los escribanos se encargarían de elaborar el escrito final que, una vez sellado con el sello de la audiencia, es autorizado por el notario $^{36}$. Escribanos y notarios han de prestar juramento acerca del recto cumplimiento de su oficio ${ }^{37}$.

Se detecta, en ocasiones, la presencia de los notarios del número en las sesiones del tribunal; este hecho se relaciona con el traslado de documentos, la ejecución de últimas voluntades, testimonios de cumplimiento de la sentencia, etc., cuestiones habitualmente encomendadas a los notarios públicos de las villas.

Es muy posible que existiera entre estos funcionarios una cierta división del trabajo, ya que el ámbito de acción de los notarios apostólicos tiene un límite claro en el reino castellano. Efectivamente, en 1329 el rey Alfonso XI prohibió en las Cortes de Madrid a los notarios apostólicos el ejercicio de la profesión fuera de la esfera eclesiástica; el veto fue renovado por Enrique II y Juan II ${ }^{38}$. Dado que a la audiencia arzobispal llegan

\footnotetext{
${ }^{34}$ Es decir, aquellos notarios que siendo nombrados por el arzobispo no estan adscritos a ningún territorio.

${ }^{35}$ JUSTO MARTÍN, M.X.; LUCAS ÁLVAREZ, M.: Fontes documentais da Universidade de Santiago. Santiago, 1991, doc. $n^{\circ} 346,347,348$, 349, etc.; RODRÍGUEZ NÚÑEZ, C.C.: «La colección documental de Santa Clara de Santiago (1196 a 1500)» en Liceo Franciscano. $2^{\mathrm{a}}$ época, XLV (1993), n 1323; ACS, Leg. 669 A-B, fo 79r; ACS, Carpeta Sueltos 16, $\mathrm{n}^{\circ}$ 18; ACS, Carpeta Sueltos 20, $\mathrm{n}^{\circ} 30-1$; ACS, Tumbo $\mathrm{H}, \mathrm{f}^{\circ}$ 9, $2^{\mathrm{a}}$ fol. $\mathrm{f}^{\mathrm{o}} 27 \mathrm{r}$; ACS, Tumbo D, $\mathrm{f}^{\circ} 37 \mathrm{r}$; ACS, Tumbo de Tenencias $3^{\circ}$, $\mathrm{f}^{\circ}$ 325r, 329r; AHDS, FSMP, Leg. $12, \mathrm{f}^{\circ} 12 \mathrm{v}, 198 \mathrm{v}, 199 \mathrm{v}$ y ss.

${ }^{36}$ una cum prenominatis testibus presens fui eaque omnia et singula sic fieri vidi et audivi ac in nota supresi, ex qua hunc presentem titulum siue hoc presens publicum instrumentum per alterius manum, me ocupato, conscriptum extraxi et publicaui (JUSTO MARTÍN, M.X.; LUCAS ÁLVAREZ, M.: op. cit., nº 348, 346, 347, 351).

${ }^{37} \mathrm{Vd}$. supra nota 31. Así ocurre también en otras audiencias (DUERR, C.J.: The judicial notary. Washington, 1951).

${ }^{38}$ BONO HUERTA, J.: Historia del derecho notarial español. 2v. Madrid, 1979 y 1982; v. I.2, pp. 216-219; PASCUAL MARTÍNEZ, L.: «Estudios de diplomática castellana. El documento privado y público en la Baja Edad Media: los escribanos» en Misce-
} 
casi todo tipo de causas (espirituales y temporales), unas remitidas por los diferentes tribunales de la Tierra de Santiago y otras en primera instancia, es razonable suponer que en algunas de ellas intervinieron personas ajenas al estamento clerical. Sin duda esto debió ser frecuente en aquellos asuntos que permitían apelación a los tribunales reales. En todo caso, sí parece existir una cierta división del trabajo ya que, según los indicios, cada proceso es escriturado por un mismo escribano ${ }^{39}$.

En otras cortes eclesiásticas, el trabajo cotidiano de escritores y notarios está supervisado por el registrador o canciller, cuya presencia no registran las fuentes compostelanas, pero que posiblemente existió. Este funcionario tendría como misión fijar la hora y el orden de las vistas orales, la designación de escribanos para las causas y la supervisión general de la escrituración ${ }^{40}$. La persona elegida para ocupar este cargo, ha de contar con una gran preparación teórica y práctica y tener, necesariamente, conocimientos del oficio notarial ya que sobre él asume las funciones de dirección de este despacho.

\section{EL ITER DOCUMENTAL}

Resulta casi imposible establecer el proceso documental en esta oficina, dado que la información proporcionada por las fuentes es muy avara en esta cuestión; se hace necesario sustituir las lagunas con noticias procedentes de despachos similares ${ }^{41}$. Aunque la actividad del provisor es

lánea Medieval Murciana, VIII (1981), pp. 119-190, p. 139. El ámbito de ejercicio de estos notarios apostólicos aparece recogido en los nombramientos pontificios del siglo $\mathrm{XV}$, que lo restringen claramente a las causas eclesiásticas.

${ }^{39}$ ACS, Carpeta Sueltos 16, ${ }^{\circ}$ 10-3; ACS, Carpeta Sueltos, 16, 32.

${ }^{40} \mathrm{Un}$ oficial con estas funciones aparece en los tribunales británicos (WOODCOCK, B.L.: Medieval ecclesiastical, pp. 38-40) y marselleses (AUBENAS, R.: Recueil de lettres des officialités de Marseille et d'Aix (XIV ${ }^{e}-X V^{e}$ s.), Paris, 1937; p. XXVI). Para el caso francés P. Fournier define su obligación de llevar un registro de las causas y asuntos de la audiencia (IDEM: Les officialités, pp. 28-29). La existencia de un personaje con estas atribuciones en Santiago no puede confirmarse ni desmentirse.

${ }^{41}$ AUBENAS, R.: op. cit., pp. XXVII-XXIX; DUERR, C.J.: op. cit., pp. 15-16; PUNCUH, D.: «Note di diplomatica giudiziaria savonese» en Atti della Societa Ligure di Storia Patria. Nuova Serie, V (1965): pp. 13-17.

"CUADERNOS DE ESTUdIOS GALLEGOS", Tomo XLV, Fascículo 110, Santiago 1998. 
eminentemente judicial, no todos los asuntos se desarrollan por cauces procesales (por ejemplo, los incluidos en el ámbito de la jurisdicción graciosa). Las peticiones y las demandas (denuncias) se presentan ante el juez oralmente o por escrito y quedarían consignadas en las actas del tribunal literalmente o como anexo a las notas del escribano. En algunas audiencias estos documentos son presentados directamente ante el escribano que las lee en la vista.

En las causas que se determinan por la vía procesal (es decir, cuando no hay acuerdo entre las partes o bien cuando ha de confirmarse la existencia de un derecho) las escrituras entran en la audiencia a medida que el pleito se va desarrollando: pruebas periciales, interrogatorios testificales, pesquisas y documentación probatoria alegada por las partes o solicitada por el juez; todo ello es incluido en el expediente del proceso a medida que llega al tribunal. De los escritos producidos por una entidad externa -por ejemplo, un notario público- se adjunta una copia autorizada por el juez o presentada por las partes que se incluye en los registros del proceso, textual o sumariamente. Asimismo, se elaboran copias de los documentos y actas del proceso para las partes contrarias, con el fin de que puedan ser examinados y aceptados o rebatidos.

En los otros negocios, por ejemplo la concesión de beneficios, licencias, dispensas o absoluciones, la petición muy posiblemente se presenta oralmente o por escrito ante un funcionario de la audiencia; es confirmada o rechazada por el juez en despacho privado con un escribano o con el registrador.

Finalmente, la decisión del provisor (sentencia, mandato, dispensa, etc.) es escriturada por los escribanos y firmada por el juez y el notario ${ }^{42}$ y sellada con el sello de la audiencia ${ }^{43}$, tasada y entregada el interesado ${ }^{44}$. Algunos de estos textos necesitan para su completa validez, ciertos requisitos de publicidad. Las sentencias han de ser leídas en el tribunal ante las

${ }^{42}$ Con frecuencia, la intervención notarial se limita a una rúbrica acompañada del nombre del oficial.

${ }^{43}$ Las tasas por la aposición del sello pertenecen a la mesa arzobispal (ACS, Tumbo G, fo 29r). JUSTO MARTÍN, M.X.; LUCAS ÁlVAREZ, M.: Fontes documentais, $\mathrm{n}^{\circ}$ 272, 273; PORTELA SILVA, M.J.: La colección, $\mathrm{n}^{\circ}$ 1329; ACS, Carpeta Sueltos 16, $\mathrm{n}^{\circ} 17$.

${ }^{44}$ Los documentos llevarían la nota de su precio en las esquinas inferiores o al dorso (ACS, Carpeta Sueltos 19, n 6, 12, 15, 16).

"CUADERNOS DE ESTUDIOS GALLEGOS", Tomo XLV, Fascículo 110, Santiago 1998. 
partes ${ }^{45}$; las cartas de monición, excomunión y algunos mandatos son difundidos públicamente al igual que ocurre con algunos documentos arzobispales cuando su información se considera de interés general; los escritos que atañen a particulares son leídos al afectado y divulgados -en el caso de excomunión- en la iglesia parroquial en presencia de toda la feligresía.

Inicialmente el procedimiento de registración en estas audiencias se lleva a cabo en un solo libro, que recoge todo tipo de asuntos ocurridos ante el tribunal; más tarde, al igual que ocurre en las cancillerías episcopales se produce una diversificación y nacen nuevas series de registros. En ellos se redactan las noticias en una doble variante: el texto completo (más raros cuanto más se avanza en el tiempo) o simplemente la reseña (lo más frecuente especialmente en el caso de documentos muy sujetos al formulario).

Por lo general, las audiencias diocesanas dispusieron de un registro denominado matricula causarum, verbalia o registra curie donde se recoge el trasunto de los procesos vistos por el tribunal; en ellos se redactan, partiendo de las actas del secretario, los acontecimientos de los pro$\operatorname{cesos}^{46}$. Sin duda esta es la serie más variada, ya que los regestos afectan a todo tipo de asuntos tratados en la corte. Los registros especiales recogen normalmente temas repetitivos tales como licencias o dispensas, excomuniones, colaciones de beneficios, etc. Por ello, sólo se consigna el nombre del destinatario y el objeto del documento emitido (el beneficio, la pena, la excomunión o la penitencia), la fecha, las tasas y el nombre del notario que lo redactó. Son los libri licentiarum, con las licencias y dispensas $^{47}$; los liber collationum o registra collationum, que enumeran las colaciones y provisiones de beneficios eclesiásticos ${ }^{48}$.

${ }^{45}$ Esta circunstancia queda, en ocasiones, registrada en el propio documento: PORTELA SILVA, M.J.: La colección, ${ }^{\circ}$ 1329; ACS, Carpeta Sueltos 16, $\mathrm{n}^{\circ} 17$.

${ }^{46}$ AUBENAS, R.: op. cit. p. XXVII; HILLGARTH, J.N.; SILANO, G.: The register 'notule communium 14' of the diocese of Barcelona (1345-1348). Toronto, 1983; pp. 2-3; DUERR, C.J.: The judicial, p. 16.

${ }^{47}$ CÁRCEL ORTI, M.M.: «El documento episcopal. Estado actual de sus estudios» en Boletín de la Sociedad Castellonense de Cultura, LIII (1982), pp. 471-511; p. 477; IDEM: «Notas de diplomática episcopal: títulos de órdenes sagradas» en Hispania Sacra, XLV (1993), pp. 430-485; p. 477.

${ }^{48}$ CÁRCEL ORTI, M.M.: Notas de diplomática.

"CUADERNOS DE ESTUDIOS GALLEGOS", Tomo XLV, Fascículo 110, Santiago 1998. 
La documentación compostelana es parca en informaciones sobre este tipo de instrumentos y no puede confirmarse la existencia de registros. Algunos testimonios corroboran la presencia de procedimientos de registro y control que, sin embargo, apuntan en otra dirección. Buena parte de la documentación al ser elaborada por notarios adscritos a este despacho, quedaría registrada en sus protocolos. Esta obligación se recoge clara y específicamente en los nombramientos de notarios apostólicos y reales ${ }^{49}$ y la documentación compostelana confirma esta práctica ${ }^{50}$. En estos libros se copian todos los documentos elaborados por el notario en esta oficina y abarcarían una amplia variedad de escritos, desde la colación y provisión de beneficios hasta las sentencias ${ }^{51}$. Dado que algunos de estos notarios ejercen también su profesión fuera de la audiencia, es fácil suponer que dispongan de un registro diferenciado para los asuntos de la audiencia, que quedaría en ella a su muerte y sería entregado a sus sucesores en el oficio ${ }^{52}$. Como ya se ha dicho, posiblemente existieron registros diferenciados de licencias para predicar y de clérigos ordenados.

Estas parcas noticias pueden completarse -siempre con las precauciones necesarias- con las procedentes de otras audiencias gallegas. El sínodo tudense de 1528 recoge interesantes disposiciones sobre los tribunales episcopales y su documentación ${ }^{53}$. Sus cánones constituyen una verdadera recopilación de derecho diocesano elaborado por personajes

\footnotetext{
${ }^{49}$ No aparece esta obligación en los nombramientos de los escribanos de la audiencia, aunque posiblemente éstos también tendrían obligación de conservar los textos que pasaron ante ellos.

${ }^{50}$ Se menciona una relación extraída por un notario de la audiencia de los títulos y colaciones que pasaron ante su antecesor (AHDS, FG, Leg. 501, 2, $\mathrm{f}^{\circ} 68 \mathrm{v}$ ). Esta noticia no tiene referente cronológico, sin embargo, por los nombres de los notarios (Alonso Galos y Diego de Salamanca) puede datarse en los últimos decenios del siglo XV. También se menciona su uso a la hora de elaborar nuevos ejemplares de documentos anteriormente otorgados (JUSTO MARTÍN, M.X.; LUCAS ÁLVAREZ, M.: Fontes documentais, $\left.\mathrm{n}^{\circ} 346,349,352,354,358\right)$.

${ }^{51} \mathrm{La}$ existencia de estos registros generales se constata también en otras sedes (MICHEL, F.: Zur Geschichte, p. 146).

${ }^{52}$ Así ocurre al menos durante el período del arzobispo Fonseca (JUSTO MARTÍN, M.X.; LUCAS ÁLVAREZ, M.: Fontes documentais, $\mathrm{n}^{\circ} 346,349,352$, 354, 358; AHDS, FG, Leg. 501, 2, $\mathrm{f}^{\mathrm{o}}$ 68v.

${ }^{53}$ GARCÍA Y GARCÍA, A. (dir): Synodicon, Synod. Tud. 1528, L. 2., T. 1.
}

"CUADERNOS DE ESTUDIOS GALLEGOS", Tomo XLV, Fascículo 110, Santiago 1998. 
versados en derecho canónico y en los ordenamientos de sínodos anteriores; por ello, en ocasiones se recogen mandatos cuyo cumplimiento se constata en la diócesis desde tiempo atrás, otras veces se modernizan prácticas anteriores. Confirma la existencia de registros de procesos en los que se incluyen los documentos presentados ante la corte ${ }^{54}$; prescribe la elaboración de un libro de penas, que está en posesión del notario más antiguo de la audiencia, donde los escribanos anotan las condenas que ante ellos pasaron, con la fecha, la sanción y el nombre del reo. En este mismo libro se han de consignar las colaciones de beneficios, luctuosas, licencias de ausencia y dimisorias ${ }^{55}$. Asimismo, se constata la elaboración de protocolos notariales como los descritos en la audiencia compostelana ${ }^{56}$.

Una vez elaborados y registrados los documentos, el personal de la audiencia los tasa. El precio de la escritura se marca en una de las esquinas inferiores o bien al dorso. La única relación de aranceles de escrituras que se conserva en la diócesis compostelana, se remonta al período de $\mathrm{D}$. Juan Arias y se aplica a los instrumentos confeccionados por los notarios de Santiago ${ }^{57}$. Una provisión de los Reyes Católicos, dada en Madrid en 1495 , informa sobre algunos problemas y abusos cometidos por los escribanos del tribunal emplazado en la plaza de la Quintana ${ }^{58}$. Estos oficiales cobraban cinco maravedís por una carta de excomunión y diez por las demás; sin embargo, han subido los precios sin consentimiento y sin capacidad para hacerlo. Nuevamente, hay que acudir al sínodo de Tui de 1528 para encontrar una tabla de aranceles completa ${ }^{59}$. Según se aprecia en este documento, cada tipo de escritura tiene un valor, que se acrecienta en el caso de aquellas que han de ser selladas. Los ingresos se destinan al escribano o notario, a la dependencia del sello (cuyas rentas pertenecen al prelado) y a la audiencia ${ }^{60}$.

\footnotetext{
${ }^{54}$ GARCÍA Y GARCÍA, A. (dir): Synodicon, Synod. Tud. 1528, L. 2., T. 1 . c. 8.

${ }^{55}$ Ibidem, Synod. Tud. L. 5., T. 6., c.1.

${ }^{56}$ Ibid. Synod. Tud. 1528, L. 5., T. 6., c. 4.

${ }^{57}$ VÁZQUEZ BERTOMEU, M.: La institución notarial y el cabildo compostelano (1460-1481). Tesis doctoral en microficha. Santiago, 1996; v. I, pp. 227-228.

${ }^{58}$ Archivo General de Simancas, Registro General del Sello, 1495-2-6, 1495-6-25.

${ }^{59}$ GARCÍA Y GARCÍA, A. (dir): Synodicon, v., Synod. Tud. 1528, L. 2, T. 1 , c. 8.

${ }^{60}$ Ibid., Synod. Aur. 1543-44, T.. 37, c. 1.
}

"CUADERNOS DE ESTUDIOS GALLEGOS", Tomo XLV, Fascículo 110, Santiago 1998. 


\section{LOS DOCUMENTOS}

Los documentos producidos por la audiencia y elaborados por sus empleados presentan una doble vertiente según los ámbitos de acción del oficial o provisor: por un lado están las escrituras relacionadas con el ejercicio de la jurisdicción contenciosa y criminal, por otro las vinculadas a la jurisdicción graciosa. En el primer caso se trata de instrumentos eminentemente procesales, en el segundo entra una gran variedad de licencias o nombramientos.

\subsection{Las escrituras procesales}

Abarcan una tipología extensa de textos; unas nacen directamente de las actuaciones del magistrado (por ejemplo, las sentencias o las citaciones), otras de la escrituración de actos verbales (libelo de denuncia o deposiciones testificales). Del mismo modo, algunas se redactan en la propia audiencia, otras - como los testimonios de publicidad o las pesquisas- fuera de ella. En cualquier caso, todas ellas tienen como punto de referencia la actuación del tribunal.

Las vistas ante el provisor originan una importante variedad de textos, directamente relacionados con el desarrollo del proceso en sus diferentes fases. El procedimiento seguido es el establecido para el ámbito eclesiástico, que renueva las tradiciones procesales del reino leonés ${ }^{61}$. La denuncia o libellus conventionis del actor o demandante, que es presentada por escrito o bien redactada por un escribano de la audiencia, da comienzo al juicio $^{62}$; ha de contener claramente los datos básicos de la demanda: quién

${ }^{61}$ La influencia de los usos procesales clásicos en la legislación del reino leonés a través del Liber Iudiciorum es innegable (PRIETO MOREIRA, A.: «El proceso en el reino de León a la luz de los diplomas» en El reino de León en la Alta Edad Media: Ordenamiento jurídico del reino. León, 1992; pp. 383-518) Sobre el proceso romanocanónico vd. GARCÍA Y GARCÍA, A.: El proceso canónico en la documentación medieval leonesa; FOURNIER, P.: op. cit. En la procedura eclesiástica, los procesos civiles y los criminales apenas se diferencian en sus fases y desarrollo.

${ }^{62}$ En las causas a las que se aplica la procedura sumaria, la denuncia se concreta en una exposición oral que el secretario resume en las actas (GARCÍA Y GARCÍA, A.: op. cit., pp. 77-78).

"CUADERNOS DE ESTUdiOS GALLEGOS", Tomo XLV, Fascículo 110, Santiago 1998. 
demanda, qué pide, ante qué juez y en qué derecho basa su actuación; una copia de este escrito es entregado a la parte demandada. Las citationes o mandatos judiciales convocan a las partes ante el magistrado, a lo largo del proceso se elaboran también este tipo de cartas para llamar a los testigos; han de contener las indicaciones sobre el momento y lugar de la comparecencia. Cuando las partes no comparecen personalmente, habrán de mostrar sus representantes los mandatos procuratorios que les autorizan a actuar.

En la vista oral, las actuaciones quedan registradas en las actas que redacta el escribano. Durante la sesión éste toma nota de lo acontecido; más tarde, estos apuntes son redactados incluyéndose -habitualmente de modo literal- los escritos alegados por las partes, las preguntas hechas a los testigos o las exposiciones de los procuradores. De otros sucesos tales como los juramentos, el escribano se limita a recoger su existencia y dar fe de ellos ${ }^{63}$.

Para sustentar sus derechos, las partes presentan pruebas. El sistema probatorio admite -según el derecho- varias modalidades ${ }^{64}$ : interrogatorio del demandado y los testigos, la confesión del acusado -que da fin al proceso-, las pruebas documentales y los testimonios periciales. Casi todas estas actuaciones tienen lugar ante el juez y el notario que llevan la causa. Finalmente, los contendientes realizan un alegato final replicando los derechos y exposición de la parte contraria y reafirmando la suya. Las actas del proceso son utilizadas por el juez para dictar sentencia y en ocasiones se dan traslados para las partes ${ }^{65}$.

Tras la vista, el juez procede a dictar sentencia. Estas pueden ser de dos tipos: interlocutoria -cuando se refiere a un aspecto de la causa-o definitiva -pone fin al proceso-. La primera no necesariamente ha de redactarse en pública forma, bastando con que quede registrada en las actas. La segunda -redactada por el notario- ha de ser promulgada y leída

${ }^{63}$ Así ocurre al menos en el tribunal de la Quintana (ACS, Carpeta Sueltos 16, $\mathrm{n}^{\circ} 10$ 3; ACS, Carpeta Sueltos 16, $\mathrm{n}^{\circ} 32$ ) y lo corroboran los precarios testimonios procedentes de la audiencia (ACS, Leg. 669 A-B, $\mathrm{f}^{\mathrm{o}}$ 137r-138r).

${ }^{64}$ GARCÍA Y GARCÍA, A.: op. cit., pp. 73-74.

${ }^{65}$ AHDS, FG, Leg. 501, 1, fo 1r, 1v; AHDS, FG, Leg. 501, 2, fo 19v, $21 \mathrm{v}$.

"CUADERNOS DE ESTUDIOS GALLEGOS", Tomo XLV, Fascículo 110; Santiago 1998. 
ante los litigantes ${ }^{66}$. En caso de disconformidad las partes presentarán su apelación ante el tribunal superior ${ }^{67}$.

Una vez dictada, la sentencia habrá de ser ejecutada. Esta iniciativa corresponde al juez ordinario que manda elaborar el correspondiente mandamiento (carta ejecutoria). También incumbe al magistrado decidir el coste del proceso ${ }^{68}$ (declaración de costas).

Las escrituras que pasaron ante el provisor compostelano se conservan en escasa medida y la información que nos proporciona ha de completarse con las verbalidades de procesos vistos por los jueces de la Quintana ${ }^{69}$. Estas permiten observar que se sigue el procedimiento arriba descrito: presentación de las partes, pruebas documentales cuya copia se incluye en el proceso (si bien no en las notas instantáneas del secretario judicial), citaciones, deposición de los testigos, alegatos finales y finalmente la sentencia. La documentación conservada registra, asimismo, la existencia de escritos que aparecen únicamente referidos en actas, sentencias y otros testimonios: citaciones, mandatos judiciales, requisitorias, licencias, absoluciones, etc. ${ }^{70}$. Es de suponer la presencia de otros de los que no nos ha quedado noticia: libelos de denuncia, testimonios de publicidad de las citaciones y del juramento de los testigos, procuraciones, traslados del proceso, partes de él y de los documentos presentados como pruebas, mandamientos y ejecutorias para el cumplimiento de las sentencias interlocutorias, cartas de rebeldía, apelaciones, etc. ${ }^{71}$

La documentación conservada relacionada con la audiencia compostelana consiste generalmente en textos conservados por alguna de las partes por su valor probatorio. Son informaciones testificales sobre un derecho, pesquisas e informaciones realizados por orden judicial; en ellas, el juez local o el procurador de uno de los litigantes, acude con un mandamiento (que generalmente incluye la amenaza de excomunión) al lugar

\footnotetext{
${ }^{66}$ GARCÍA Y GARCÍA, A.: op. cit., pp. 75-76.

${ }^{67}$ PORTELA SILVA, M.J.: La colección, nº 1329; ACS, Leg. 1102 A, s.f. 1486-4-8.

${ }^{68}$ GARCÍA Y GARCÍA, A.: op. cit., p. 77.

${ }^{69}$ ACS, Carpeta Sueltos 16, ${ }^{\circ} 10-3$; ACS, Carpeta Sueltos 16, $\mathrm{n}^{\circ} 32$.

${ }^{70}$ vd. nota supra. ACS, Leg. 1102 A, s.f. (1486-8-4); AHDS, FG, Leg. 501, 2, fo 14r, $41 \mathrm{r}, 42 \mathrm{v}$.

${ }^{71}$ GARCÍA Y GARCÍA, A. (dir): Synodicon, Synod. Tud. 1528, L. 2, T. 1.
}

"CUADERNOS DE ESTUDIOS GALLEGOS", Tomo XLV, Fascículo 110, Santiago 1998. 
donde se procede al interrogatorio de los testigos; este escrito se realiza ante el notario público del lugar o ante uno contratado por la parte a tal efecto $^{72}$.

Se conserva, asimismo, un importante número de sentencias definitivas; en su tenor, el juez expone brevemente el asunto en discusión, las actuaciones del proceso y la parte que ha probado sus intenciones; este documento va firmado por el juez y un notario, llevando al dorso el sello de cera roja de la audiencia ${ }^{73}$. Algunos de estos documentos relatan con cierta minuciosidad los pormenores de la vista.

Los mandamientos judiciales constituyen, sin duda, el grupo más amplio y de mayor variedad y se refieren tanto a las diversas partes del proceso como a la sentencia; su estructura es claramente dispositiva y ejecutoria; han llegado hasta nosotros en su versión original o -más frecuentemente- insertados o mencionados en otros textos ${ }^{74}$. Abarcan el amplio espectro temático de las causas de la audiencia: mandamientos para que los testigos declaren en las pesquisas, para que se dé posesión de un bien, para que se admita a un clérigo en un beneficio, para que se paguen las costas, para que se ejecute la sentencia, etc. En ellas se hace un llamamiento para que se ejecute una orden judicial incluyendo en su cláusula de sanción la amenaza de excomunión. Reciben varias denominaciones, siendo las más frecuentes la de mandamiento, carta monitoria y carta de se.

${ }^{72}$ JUSTO MARTÍN, M.J.; LUCAS ÁLVAREZ, M.: Fontes documentais, $\mathrm{n}^{\circ}$ 273, 281, 313; RODRÍGUEZ NÚÑ̃E, C.C.: La colección, nº 639. ACS, Cofradía de la Concepción, Libro de Hacienda 1, fo 71v-73r, 152r; ACS, Carpeta Sueltos 19, nº 9; ACS, Leg. 1257 B', s.f. (1498-4-9); ACS, Leg. 221, f 1r-8r, 8r-14r; ACS, Leg. 669 A-B, f f $^{\circ}$ 137r138r; AHDS, FG, Leg. 501, 1, fo 1v.

${ }^{73}$ JUSTO MARTÍN, M.J.; LUCAS ÁLVAREZ, M.: op. cit., n 284 ; PORTELA SILVA, M.J.: La colección, $\mathrm{n}^{\circ}$ 1329; RODRÍGUEZ NÚÑEZ, C.C.: op. cit., $\mathrm{n}^{\circ}$ 712, 1046, 1323, 1340; ACS, Leg. 129, fo 8r; ACS, Carpeta Sueltos 16, nº 7, 17, 20; ACS, Carpeta Sueltos 19, $\mathrm{n}^{\circ}$ 6, 9, 16; ACS, Carpeta Sueltos 20, $\mathrm{n}^{\circ}$ 62; ACS, Leg. 1102 A, s.f. (14869-6).

${ }^{74}$ JUSTO MARTÍN, M.X.; LUCAS ÁLVAREZ, M.: op. cit., nº 272, 312. ACS, Carpeta Sueltos 19, $\mathrm{n}^{\circ} 13,14,16$; ACS, Carpeta Sueltos 16, $\mathrm{n}^{\circ}$ 18-1; ACS, Carpeta Sueltos 20, n $^{\circ} 62$; ACS, CC, Libro de Hacienda 1, fo 71v-73v; ACS, Leg. 1102 A, s.f. (1486-10$20)$.

"CUADERNOS DE ESTUdiOS GALLEGOS", Tomo XLV, Fascículo 110, Santiago 1998. 


\subsection{Otros tipos documentales}

Las audiencias episcopales ven también nacer tipologías documentales no estrictamente relacionados con actividades procesales sino con el deber de los prelados como garantes del cumplimiento de las normas de la Iglesia y pastores de almas. Nacen así licencias para desposar sin moniciones previas, absoluciones de casamientos clandestinos, de excomuniones a vivos y muertos, licencias para abrir sepulturas, interposición de decreto para autorizar documentos, licencias para predicar o confe$\mathrm{sar}^{75}$, etc. Pero también procesos matrimoniales, por falsos juramentos, usura, etc. Apenas queda rastro de estas escrituras en los archivos compostelanos.

Otros testimonios referentes a la actuación del juez presentan escritos referentes al derecho familiar y testamentario. Son las causas vistas acerca de los testamentos, su apertura y ejecución y las asignaciones de curadores o tutores y la protección de los bienes del menor. Fruto de estas acciones surgen los testimonios de apertura de testamentos ${ }^{76}$, los mandatos sobre almoneda de bienes ${ }^{77}$, reparto de la herencia ${ }^{78}$, cartas de curaduría y tutoría ${ }^{79}$, licencias para vender o empeñar los bienes de menores, etc. Generalmente todos estos documentos se caracterizan por su fuerte carácter testimonial ya que su tenor básicamente incide en recoger una actuación judicial: se nombra un tutor que se comprometió ante el juez a cumplir unas normas; se procede a la lectura de un testamento que el magistrado da por válido y cuyo traslado y ejecución autoriza, etc.

Para reforzar el cumplimiento de las disposiciones de sus jueces, la Iglesia dispone de instrumentos específicos como son las censuras eclesiásticas que van desde la monición o amenaza hasta la excomunión e

\footnotetext{
${ }^{75}$ GARCÍA Y GARCÍA, A. (dir): Synodicon, Synod. Tud. 1528, L. 2, T. 1.

${ }^{76}$ RODRÍGUEZ NÚÑEZ, C.C.: La colección, $\mathrm{n}^{\circ}$ 1039; ACS, Leg. 669 A-B, fo 2r-2v, $10 \mathrm{r}-11 \mathrm{v}, 44 \mathrm{r}-49 \mathrm{v}$.

${ }^{77}$ ACS, Leg. 669 A-B, $\mathrm{f}^{\mathrm{D}} 32 \mathrm{r}-33 \mathrm{v}$.

${ }^{78}$ ACS, Leg. 669 A-B, fo 50r-54r.

${ }^{79}$ VIADER SERRA, J.: El Archivo del monasterio de Santa Clara de Santiago y estudio de su documentación durante el siglo XV. Colección diplomática. Tesis de Licenciatura inédita. Santiago de Compostela s. d.; doc. $n^{\circ} 65$.
}

"CUADERNOS DE ESTUDIOS GALLEGOS", Tomo XLV, Fascículo 110, Santiago 1998. 
interdicto $^{80}$. La excomunión con frecuencia es administrada por las dignidades -personajes con jurisdicción eclesiástica-de la diócesis tales como el deán o los arcedianos además de los jueces arzobispales. Las dificultades de los tiempos provocaron que en la segunda mitad del siglo XV -seguramente por el gran número de ellas promulgadas- su efectividad sea más bien escasa; por ello, el arzobispo Fonseca, reservó para sí y su provisor el derecho a emitirlas ${ }^{81}$. Estas cartas de censura eclesiástica son publicadas en el templo catedralicio, leídas al interesado y divulgadas en su comunidad parroquial ${ }^{82}$. Dado que normalmente el excomulgado es absuelto, su conservación es difícil; las que han llegado hasta nosotros proceden de los fondos capitulares como parte de disputas y procesos contra particulares.

La audiencia realiza además -seguramente en virtud de mandatos especiales- algunas funciones propias de una escribanía arzobispal, ya que corresponde al arzobispo autorizar procesos que se inician por indultos, gracias y otras cartas apostólicas ${ }^{83}$. Fruto de esta intervención serán, por ejemplo, las cartas monitorias exhortando a cumplir los mandatos apostólicos o los títulos de concesión de beneficios.

Los documentos emanados de la audiencia van siempre intitulados por el provisor, adquiriendo por lo general formas próximas a las de los textos emanados de las secretarías arzobispal, real y pontificia, en los que el magistrado es auxiliado únicamente por un escribano. Todo un engranaje de profesionales de la escritura trabaja a su servicio.

${ }^{80}$ RODRÍGUEZ NÚÑEZ, C.C.: La colección, $\mathrm{n}^{\circ} 775,893$; VIADER SERRA, J.: op. cit., $\mathrm{n}^{\circ}$ 125; ACS, Leg. 669 A-B, $\mathrm{f}^{\circ}$ 50-54; ACS, Leg. sin numerar, Tenencia de Sabardes, s.f.1406-8-7.

${ }^{81}$ ACS, Leg. 669 A-B, fo 311r (al dorso).

${ }^{82}$ GARCÍA Y GARCÍA, A. (dir): Synodicon, v.I, Synod. Aur. 1543-44, T. 19, c. 1; ACS, Carpeta Sueltos 16, $\mathrm{n}^{\circ}$ 18-1 (al dorso), 26; ACS, Carpeta Sueltos 19, $\mathrm{n}^{\circ}$ 16; AHDS, FG, Leg. 501, 2, fo 46r.

${ }^{83}$ ACS, Carpeta Sueltos 16, $\mathrm{n}^{\circ} 12$; ACS, AC II, fo $111 \mathrm{r}$.

"CUADERNOS DE ESTUDIOS GALLEGOS", Tomo XLV, Fascículo 110, Santiago 1998. 
De la variedad y volumen de la documentación otorgada en la audiencia se deduce su papel como la más importante oficina de la administración arzobispal en lo que a elaboración de documentos se refiere. Sin duda, estos son los más rutinarios, quedando para el despacho personal del prelado aquellos asuntos de mayor importancia o más directamente ligados a la dignidad. No es ésta la única diócesis en la que el vicario o provisor asume tan amplias facultades. Los obispos, ocupados en sus negocios o ausentes de la sede, delegaron en estos personajes altamente competentes buena parte de sus funciones.

Esto da lugar al nacimiento de una institución profundamente vinculada al hecho escrito, donde se desarrolla siempre una mínima organización del proceso documental, existe personal especializado, tipos documentales específicos o incluso un procedimiento de actuación claro y preciso. Posiblemente a causa de todo ello, podría calificarse a la audiencia del provisor como la entidad, diplomáticamente más interesante de toda la Tierra de Santiago. Desgraciadamente, sin embargo, estamos muy lejos de poder valorar con exactitud la presencia de este despacho. Si la escasez de fuentes puede aplicarse, en general, a casi todos los aspectos de la historia de este territorio, en el caso de la audiencia resulta casi dramática ya que casi todos nuestros conocimientos sobre ella provienen de noticias referenciales e indirectas. No obstante, su importancia y relevancia parece fuera de toda duda a la espera de investigaciones ulteriores. 